\title{
BMJ Open Trends in cerebrovascular diseases mortality in Serbia, 1997-2016: a nationwide descriptive study
}

\author{
Irena Ilic, ${ }^{1}$ Milena llic, ${ }^{2}$ Sandra Sipetic Grujicic $^{3}$
}

To cite: llic I, llic M, Sipetic Grujicic S. Trends in cerebrovascular diseases mortality in Serbia, 1997-2016: a nationwide descriptive study. BMJ Open 2019;9:e024417. doi:10.1136/ bmjopen-2018-024417

- Prepublication history and additional material for this paper are available online. To view these files, please visit the journal online (http://dx.doi org/10.1136/bmjopen-2018024417).

Received 25 May 2018 Revised 10 December 2018 Accepted 11 December 2018

Check for updates

(c) Author(s) (or their employer(s)) 2019. Re-use permitted under CC BY-NC. No commercial re-use. See rights and permissions. Published by BMJ.

${ }^{1}$ Faculty of Medicine, University of Belgrade, Belgrade, Serbia 2Department of Epidemiology, Faculty of Medical Sciences, University of Kragujevac, Kragujevac, Serbia ${ }^{3}$ Faculty of Medicine, Institute of Epidemiology, University of Belgrade, Belgrade, Serbia

Correspondence to

Professor Milena llic;

drmilenailic@yahoo.com

\section{ABSTRACT}

Objectives Over the last decades, mortality from cerebrovascular diseases (CVDs) has decreased in many countries. The aim of this study was to assess the trends of CVDs mortality in Serbia.

Methods Descriptive epidemiological study. Agestandardised rates (ASRs) for CVDs mortality were assessed by joinpoint regression analysis to identify significant changes in trends and estimate annual per cent changes with $95 \% \mathrm{Cl}$. The age-period-cohort analysis has been used to describe variations in mortality.

Results Over this 20-year period, there were 312847 deaths from CVDs, with the overall average annual ASR of 148.4 per 100000 . The trend of ASRs from CVDs mortality in males in Serbia showed a significant joinpoint: rates insignificantly decreased from 1997 to 2005 by $-0.8 \%$ per year $(95 \% \mathrm{Cl}-1.7 \%$ to $0.2 \%)$ and thereafter rapidly decreased by $-5.0 \%$ per year $(95 \% \mathrm{Cl}-5.6 \%$ to $-4.5 \%)$. A joinpoint for females was found in 2006: the mortality trend was first significantly decreasing by $-1.0 \%$ per year $(95 \% \mathrm{Cl}-1.9 \%$ to $-0.0 \%)$ and then sharply falling down by $-6.0 \%$ per year $(95 \% \mathrm{Cl}-6.8 \%$ to $-5.3 \%)$. Results of age-period-cohort analysis indicated that the relative risk for CVDs mortality showed statistically significant $(p<0.05)$ cohort and period effects, as well as the net drift and local drifts in Serbian population. The trends in mortality for all subtypes of CVDs were similar in both sexes: trends significantly decreased for most subtypes, with the exception of a significant increase for cerebral infarction. Conclusions After a decade of increase, CVDs mortality rates are declining in last decade in Serbia. However, mortality rates from CVDs remain exceedingly high in Serbia. Differences in mortality trends of the stroke subtypes should be taken into account in the creation of both prevention and treatment guidelines.

\section{INTRODUCTION}

Worldwide, cerebrovascular diseases (CVDs) have been the second leading cause of death in both sexes over the last decades, with considerable international differences in mortality. ${ }^{1-6}$ According to the WHO estimates, CVDs caused deaths of 6.2 million people in the world in 2015 (this represents about $11.1 \%$ of all deaths globally), up from 5.4 million $\left(10.4 \%\right.$ ) deaths in $2000 .^{3}$ Upper-middle-income countries had the

\section{Strengths and limitations of this study}

This study described cerebrovascular diseases (CVDs) mortality trends for Serbian population in the last two decades.

- The strengths of the present study include the national representation of CVDs mortality, the quality of the national death registry data, the analysis of stroke mortality by different subtypes of stroke and the application of two methods (joinpoint regression method and age-period-cohort method) for the analysis of CVDs mortality trends.

- Limitation is the inherent limitation of age-period -cohort analysis (such as collinearity among age, period and cohort effects), while temporal trend analysis in this ecological descriptive analysis at the population level does not have to necessarily apply to individuals.

highest mortality rate due to stroke with 120.9 deaths per 100000 population-the global rate was 81.9 in $2015 .{ }^{13}$

In Europe, stroke is the second most common single cause of death, accounting for nearly 1 million deaths in 2015: approximately $14 \%$ of all deaths in women and $9 \%$ of all deaths in men are from stroke. ${ }^{7}$ In the USA, stroke became the fifth leading cause of death in men and the fourth leading cause of death in women in 2015. ${ }^{8}$ However, over two-thirds of stroke deaths worldwide occur in low-income and middle-income countries, and stroke is becoming a more common cause of death in these countries. ${ }^{5}$ In China (with stroke being the leading cause of death) and India in 2010 stroke accounted for 3 million deaths (representing more than half of total deaths due to stroke in the world), which is an increase of deaths due to CVD of 0.4 million cases from 2000 to $2010 .^{39}$

Since the 1970s, death rates from CVDs have been falling rapidly in the USA, ${ }^{9}$ and many Northern, Western and Southern European countries, as well as Asian countries. ${ }^{10} 11$ Recently, decreasing trends in CVDs mortality have been observed in some 
new industrialised, and low-income and middle-income countries, including China, Russian Federation, Ukraine, Romania, Bulgaria. ${ }^{10} 12$

Globally, stroke was the major leading cause of premature mortality in 2015 , after ischaemic heart disease. ${ }^{13}$ The three main types of stroke are ischaemic stroke, intracerebral haemorrhage (ICH) and subarachnoid haemorrhage (SAH) ${ }^{14}$ From 1990 to 2010 , there was a significant increase in global ischaemic stroke burden in terms of deaths (21\% increase), and disability-adjusted life years lost due to ischaemic stroke (18\% increase), according to the findings of the Global Burden of Diseases, Injuries, and Risk Factors 2010 study. ${ }^{15}$ The global mortality rates for ischaemic and haemorrhagic stroke (including ICH and SAH) decreased between 1990 and 2010, with the majority of global stroke burden being in low-income and middle-income countries. ${ }^{6}$ Although mortality rates for all stroke types combined declined in Mexico for 1988-2012, a significantly increased mortality trend for SAH was noticed. ${ }^{16}$ The decline in stroke mortality trends in high-income countries has been attributed to progress in prevention (through control of arterial hypertension, hyperlipidaemia, tobacco, diabetes mellitus, physical inactivity) and substantially improved acute stroke care. ${ }^{6} 17$ Former studies ${ }^{1819}$ on CVDs in Serbia aimed to assess only patterns within some country regions or applied only one method for assessing the trend of mortality. The aim of this study was to assess the trends of CVDs mortality in Serbia between 1997 and 2016.

\section{MATERIAL AND METHODS \\ Data source}

Annual data on the number of deaths due to CVDscodes I60-I69 in the 10th revision of the International Classification of Diseases (ICD) - were obtained from the National Statistical Office of the Republic of Serbia for the period 1997-2016. The vast majority of deaths due to CVDs are due to stroke. For the purpose of this study, deaths from CVDs were classified into haemorrhagic stroke (by using ICD-10 codes I60-I62), cerebral infarction (by using ICD-10 code I63), stroke not specified as haemorrhage or infarction-undetermined (UND) (by using ICD-10 code I64) and remaining CVDs were classified as 'Other' CVDs (by using ICD-10 codes I65-I69). Haemorrhagic stroke included SAH (I60), ICH (I61) and other non-traumatic intracranial haemorrhage (I62). Due to a small number of deaths, data for other non-traumatic intracranial haemorrhage were included together with data for ICH in this analysis.

Data about the Serbian population were extracted from the demographic statistics database from the Statistical Office of the Republic of Serbia. Data for the Republic of Serbia, without the Autonomous Province of Kosovo and Metohia (for which data are unavailable since 1998 and which declared itself independent in 2008), were presented in this paper. The Serbian population data were provided on the basis of official censuses in 1991,
2002 and 2011, while for intercensus years the estimates of the resident population were obtained from the state Statistical Office database. The analysis was conducted on the entire Serbian population (about 7.2 inhabitants in 2016). Serbia had the largest refugee population in Europe (nearly 400000 persons), data which were included in the Serbian population and could not be set aside as a special contingent.

\section{Statistical analysis}

Crude, age-specific and age-standardised rates (ASRs, using the European standard population and by the method of direct standardisation) were calculated. Rates are expressed as deaths per 100000 persons. Age-specific mortality rates have been calculated for the age interval from 0 to 80 and over by 10 -year periods.

Mortality trends from CVDs were assessed using the joinpoint regression analysis (Joinpoint Regression Software, V.4.5.0.1-June 2017, available through the Surveillance Research Program of the US National Cancer Institute). Joinpoint analysis was performed to identify the points at which a significant change of direction in the trend occurred for CVDs mortality (also called 'joinpoints') ${ }^{20}$ The true number of joinpoints was verified with the Monte Carlo Permutation method with overall significance level of 0.05 and 4499 randomly selected data sets. ${ }^{20}$ The maximum number of joinpoints tested was five in each analysis. Grid Search method was selected. ${ }^{21}$ In the same way, the joinpoint regression analysis identifies periods of mortality data with similar rates of change. Results are presented as the annual per cent change (APC) between successive change points. In addition, the average APC over the whole 20 years of the study was calculated. ${ }^{22}$ All estimates are presented with 95\% CIs. Disparities in mortality trends according to age and gender were tested by using a comparability test-a procedure proposed by Kim et al..$^{23}$ The goal of the comparability test was to answer whether the two regression mean functions were identical (test of coincidence) or parallel (test of parallelism). The results are not shown for the subgroups aged $<20$ years, because fewer than five cases of CVDs deaths occurred in each of the decennium in any year.

Age-period-cohort analysis was performed to identify net age, period and cohort effects on CVDs mortality trend over time using the US National Cancer Institute web-based statistical tool, according to the method proposed by Rosenberg et $a l^{24}$ The age-period-cohort analysis used the overall CVDs mortality data by consecutive 5-year age groups ( 0 to 4,5 to $9, \ldots, 80$ to 84 and $85+)$, and the same 5-year intervals for calendar periods (1997 to $2001, \ldots$ and 2012 to 2016) and birth cohorts (1912 to 1916, 1917 to $1921, \ldots, 2007$ to 2011 and 2012 to 2016). Because the deceased aged 85 and over were only recorded as one group in the mortality database in Serbia, they were considered in this study together as the $85+$ age group. The estimable parameters of the age-period-cohort analysis were longitudinal age-specific rates, period and cohort rate ratios, and local drifts with net 
Table 1 Cerebrovascular diseases mortality in Serbia, 1997-2016

\begin{tabular}{lrlr}
\hline Year & Number & Crude rates & ASRs \\
\hline 1997 & 15368 & 202.2 & 174.9 \\
\hline 1998 & 16271 & 215.0 & 182.4 \\
\hline 1999 & 16698 & 221.4 & 182.0 \\
\hline 2000 & 17156 & 228.2 & 183.2 \\
\hline 2001 & 16517 & 220.1 & 172.6 \\
\hline 2002 & 16975 & 226.3 & 175.3 \\
\hline 2003 & 17511 & 234.1 & 176.5 \\
\hline 2004 & 16872 & 226.1 & 164.4 \\
\hline 2005 & 17598 & 236.5 & 168.4 \\
\hline 2006 & 17390 & 234.6 & 162.4 \\
\hline 2007 & 16958 & 229.7 & 153.8 \\
\hline 2008 & 16601 & 225.9 & 146.4 \\
\hline 2009 & 16721 & 228.4 & 144.8 \\
\hline 2010 & 16079 & 220.5 & 136.4 \\
\hline 2011 & 14367 & 197.9 & 120.4 \\
\hline 2012 & 14388 & 199.9 & 121.8 \\
\hline 2013 & 13161 & 183.7 & 108.7 \\
\hline 2014 & 12319 & 172.7 & 100.2 \\
\hline 2015 & 12549 & 176.4 & 101.1 \\
\hline 2016 & 11348 & 159.5 & 91.5 \\
\hline Overall & 312847 & 212.0 & 148.4 \\
\hline ASR. & & & \\
\hline
\end{tabular}

ASR, age standardised rate (using European standard population, per 100000 persons).

drift. Longitudinal age curve indicates the fitted longitudinal age-specific rates in reference cohort adjusted for period deviations. Local drifts, the log-linear trend by calendar period and birth cohort for each age group, indicate APCs for each age group. Net drift, the overall log-linear trend by calendar period and birth cohort, indicates the overall APC. The period rate ratios indicate variations in the rates over time that influence all age groups simultaneously. The cohort rate ratios indicate the changes of the rates across groups of individuals with the same birth years. The estimated parameters are presented with $95 \%$ CIs. Wald $\chi^{2}$ test was used for the significance of the estimable parameters. Age-period-cohort analysis was used to describe mortality trends according to sex.

A $p$ value of $<0.05$ was considered statistically significant for all tests.

\section{Patient and public involvement}

No patient or public were involved in this study.

\section{RESULTS}

Over this 20-year period, there were 312847 (137 569 males and 175278 females) deaths from CVDs, with the overall average annual ASR being 148.4 per 100000 (ASRs ranged from 183.2 per 100000 in 2000 to 91.5 per 100000 in 2016) (table 1). Average annual ASRs were 157.8/100 000 for males and 140.0/100 000 for females.

The trend of the age-standardised mortality from CVDs in males in Serbia showed a significant joinpoint: rates insignificantly decreased from 1997 to 2005 by $-0.8 \%$ per year $(95 \% \mathrm{CI}-1.7 \%$ to $0.2 \%)$ and thereafter rapidly decreased by $-5.0 \%$ per year $(95 \% \mathrm{CI}-5.6 \%$ to $-4.5 \%)$ (figure 1, table 2). A significant joinpoint for females was found in 2006: the mortality trend was first significantly decreasing by $-1.0 \%$ per year $(95 \%$ CI $-1.9 \%$ to $-0.0 \%)$ and then sharply falling down by $-6.0 \%$ per year

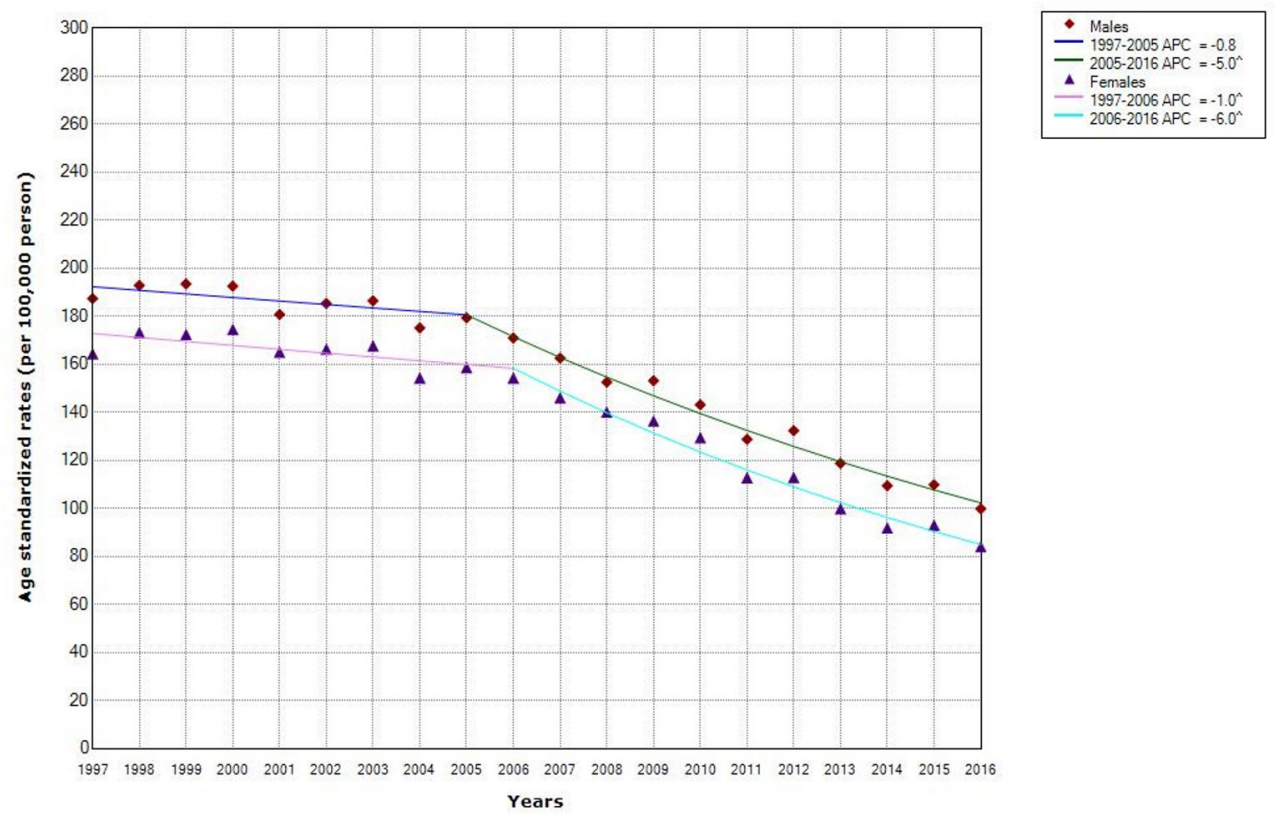

$\wedge^{\wedge}$ Indicates that the $\Lambda$ nnual Percent Change ( $\mathrm{APC}$ ) is significantly different from zero at the alpha $=0.05$ level. Final Selected Model: Males - 1 Joinpoint, Females - 1 Joinpoint. Rejected Parallelism.

Figure 1 Trends in mortality from cerebrovascular diseases in Serbia, by sexes, 1997-2016: a joinpoint regression analysis. 
Table 2 Joinpoint analysis: trends* in age-specific mortality rates from cerebrovascular diseases (per 100000 persons), males and females in Serbia, 1997-2016

\begin{tabular}{|c|c|c|c|c|}
\hline \multirow[b]{2}{*}{ Age† } & \multicolumn{2}{|l|}{ Males } & \multicolumn{2}{|l|}{ Females } \\
\hline & Period & APC (95\% Cl) & Period & APC $(95 \% \mathrm{Cl})$ \\
\hline 20-29 & $1997-2016$ & $-4.0^{*}(-7.2$ to -0.7$)$ & $1997-2016$ & $-3.5^{*}(-6.3$ to -0.5$)$ \\
\hline 30-39 & 1997-2016 & $-4.9^{*}(-6.5$ to -3.2$)$ & 1997-2016 & $-4.7^{\star}(-6.2$ to -3.1$)$ \\
\hline \multirow[t]{3}{*}{$40-49$} & 1997-2016 & $-5.2^{\star}(-5.8$ to -4.6$)$ & 1997-2004 & $-2.3(-5.9$ to 1.4$)$ \\
\hline & & & 2004-2016 & $-7.8^{\star}(-9.3$ to -6.3$)$ \\
\hline & & & Full period & $-6.1^{\star}(-7.0$ to -5.2$)$ \\
\hline \multirow[t]{3}{*}{$50-59$} & 1997-2002 & $-0.8(-4.2$ to 2.6$)$ & $1997-2000$ & $2.1(-5.7$ to 10.6$)$ \\
\hline & 2002-2016 & $-5.9^{*}(-6.6$ to -5.2$)$ & 2000-2016 & $-7.0^{*}(-7.5$ to -6.4$)$ \\
\hline & Full period $\neq$ & $-5.0^{*}(-5.6$ to -4.4$)$ & Full period & $-6.3^{\star}(-6.9$ to -5.7$)$ \\
\hline \multirow[t]{5}{*}{$60-69$} & 1997-2004 & $-1.0(-3.1$ to 1.1$)$ & $1997-2000$ & $0.7(-5.7$ to 7.5$)$ \\
\hline & 2004-2014 & $-6.6^{*}(-8.0$ to -5.3$)$ & 2000-2007 & $-4.3^{*}(-6.4$ to -2.1$)$ \\
\hline & 2014-2016 & $0.5(-14.2$ to 17.8$)$ & 2007-2014 & $-9.8^{*}(-11.8$ to -7.7 \\
\hline & Full period & $-4.6^{\star}(-5.3$ to -4.0$)$ & 2014-2016 & $-2.2(-14.3$ to 11.6$)$ \\
\hline & & & Full period & $-6.2^{\star}(-7.0$ to -5.4$)$ \\
\hline \multirow[t]{4}{*}{$70-79$} & 1997-2007 & $-0.8(-1.7$ to 0.2$)$ & $1997-2000$ & $3.3(-2.1$ to 7.0$)$ \\
\hline & $2007-2016$ & $-6.8^{*}(-7.8$ to -5.7$)$ & 2000-2009 & $-2.6^{*}(-3.5$ to -1.6$)$ \\
\hline & Full period & $-3.6^{\star}(-4.4$ to -2.8$)$ & 2009-2016 & $-9.3^{\star}(-10.4$ to -8.2 \\
\hline & & & Full period & $-4.4^{\star}(-5.3$ to -3.4$)$ \\
\hline \multirow[t]{3}{*}{$80+$} & 1997-2006 & $0.0(-1.4$ to 1.4$)$ & 1997-2006 & $0.8(-0.3$ to 1.8$)$ \\
\hline & 2006-2016 & $-3.4^{\star}(-4.6$ to -2.2$)$ & 2006-2016 & $-3.6^{\star}(-4.4$ to -2.7$)$ \\
\hline & Full period & $-1.9^{*}(-2.4$ to -1.3$)$ & Full period & $-1.6^{\star}(-2.2$ to -1.0$)$ \\
\hline \multirow[t]{3}{*}{ All ages } & 1997-2005 & $-0.8(-1.7$ to 0.2$)$ & 1997-2006 & $-1.0^{*}(-1.9$ to -0.0$)$ \\
\hline & 2005-2016 & $-5.0^{\star}(-5.6$ to -4.5$)$ & 2006-2016 & $-6.0^{*}(-6.8$ to -5.3$)$ \\
\hline & Full period & $-3.4^{\star}(-4.0$ to -2.9$)$ & Full period & $-3.7^{\star}(-4.4$ to -3.0$)$ \\
\hline
\end{tabular}

*Statistically significant trend.

†Joinpoint results are not shown for the subgroups aged $<20$ years because fewer than five cases of stroke. deaths occurred in each of the decennium in any year.

‡For full period presented average annual per cent change.

APC, annual per cent change.

(95\% CI $-6.8 \%$ to $-5.3 \%)$. According to the comparability test, mortality trends from CVDs in men and women were not parallel (final selected model rejected parallelism, $\mathrm{p}=0.0013)$.

The significantly decreasing trends in age-specific CVDs mortality rates for the whole study period were similar for men and women under 40 years (table 2). No joinpoints were identified for CVDs in men under 50 years and women under 40 years. Mortality trends for older ages were variable, with most showing a quickening in rate decrease in the most recent period. The steepest decreases in CVDs mortality rate for the study period were in women aged 50-59 years, followed by those aged 60-69 and 40-49 years. In women aged 40 and over years, non-significant increasing trends were observed at the beginning of the study period, while in men aged 50 years and over at the beginning of the study period non-significant decreasing trends were noted.
When comparing rates between types, age-standardised mortality rates for CVDs were consistently higher in men than in women throughout the period, but women had higher mortality rate for SAH (table 3). By the subcategories of stroke, cerebral infarction had the highest age-standardised mortality for both sexes except for deaths due to unspecified stroke. The trends in mortality for all subtypes of CVDs were similar in both sexes: trends significantly decreased for most disease types, with the exception of a significant increase for cerebral infarction. The rates of death over the study period were stable for 'Other' GVDs.

Results of age-period-cohort analysis of CVDs mortality in Serbian population are described in terms of four curves depicting, from left to right, trends in mortality rate by age, local drifts values with net drift, the period effects (taking 2004year as the reference) and the cohort effects (taking the 1964 birth cohort as the reference) 
Table 3 Mortality from cerebrovascular diseases in Serbia, by sexes, 1997-2016: a joinpoint analysis*

\section{Number of deaths and mortality}

\begin{tabular}{|c|c|c|c|c|c|}
\hline \multirow{3}{*}{ Males } & \multicolumn{5}{|c|}{ Number of deaths and mortality } \\
\hline & Year 1997 & Year 2016 & Number of joinpoints & AAPC & $95 \% \mathrm{Cl}$ \\
\hline & & & & & \\
\hline Deaths & 164 & 97 & & & \\
\hline ASR & 4.09 & 2.18 & 3 & $-3.4^{*}$ & -4.1 to -2.6 \\
\hline ASR & 22.38 & 15.28 & 1 & $-1.9^{*}$ & -2.6 to -1.3 \\
\hline \multicolumn{6}{|c|}{ Cerebral infarction } \\
\hline Deaths & 2030 & 2885 & & & \\
\hline ASR & 53.72 & 56.68 & 2 & $3.0^{*}$ & 1.5 to 4.5 \\
\hline \multicolumn{6}{|c|}{ ‘Other' CVDs } \\
\hline Deaths & 404 & 748 & & & \\
\hline ASR & 11.96 & 14.97 & 1 & 0.4 & -1.4 to 2.3 \\
\hline \multicolumn{6}{|l|}{ All CVDs } \\
\hline Deaths & 6952 & 5014 & & & \\
\hline ASR & 187.4 & 99.9 & 1 & $-3.4^{*}$ & -4.0 to -2.9 \\
\hline \multicolumn{6}{|l|}{ Females } \\
\hline \multicolumn{6}{|c|}{ Subarachnoid haemorrhage } \\
\hline Deaths & 277 & 188 & & & \\
\hline ASR & 41.91 & 49.31 & 2 & $3.8^{*}$ & 2.1 to 5.5 \\
\hline \multicolumn{6}{|c|}{ Stroke not specified } \\
\hline Deaths & 4490 & 697 & & & \\
\hline ASR & 87.56 & 8.96 & 1 & $-12.8^{\star}$ & -14.6 to -11.0 \\
\hline \multicolumn{6}{|c|}{ ‘Other' CVDs } \\
\hline Deaths & 572 & 1009 & & & \\
\hline ASR & 11.90 & 13.15 & 1 & 0.2 & -1.8 to 2.2 \\
\hline \multicolumn{6}{|l|}{ All CVDs } \\
\hline Deaths & 8416 & 6334 & & & \\
\hline ASR & 164.5 & 84.2 & 1 & $-3.7^{*}$ & -4.4 to -3.0 \\
\hline
\end{tabular}

*Statistically significant trend.

AAPC, average annual per cent change; ASR, age Standardised rate (per 100000 persons, using European standard population).

(figure 2). The longitudinal age curves of stroke mortality showed an accelerated increase continuously from the age of 60 years. We found that the net drift was $-4.9 \%$ $(95 \% \mathrm{CI}=-6.0 \%$ to $-3.8 \%)$ per year, and the local drift values were below 0 in all age groups, with a few insignificant exceptions at the youngest age groups. The local drift values were higher at ages $30-54$ years and decreased at ages above 55 years. Period rate ratios were in significant decline during the whole study period, especially after 2004. Cohort rate ratios showed significantly downward patterns with birth cohort increasing, but these downward tendencies were slowing down in the recent cohorts, especially for those born after the year 1962. Results of Wald tests indicated that the relative risk for 
Longitudinal Age Curve

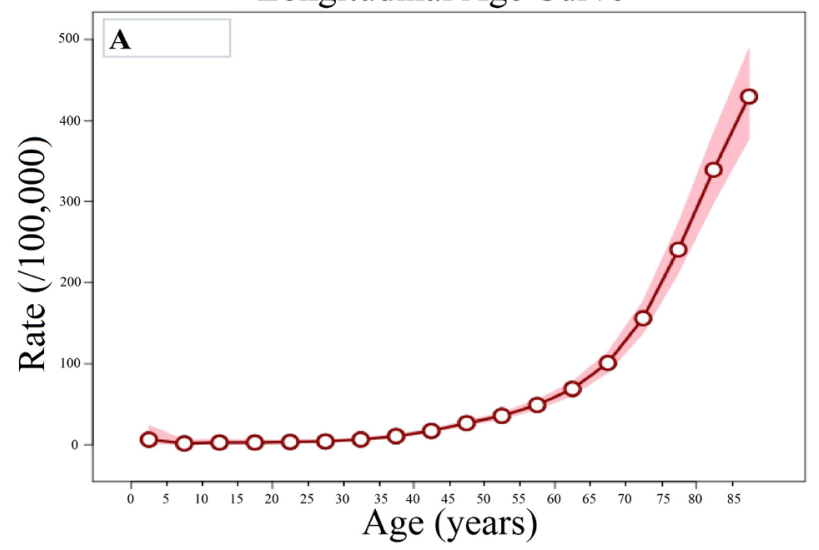

Period RR

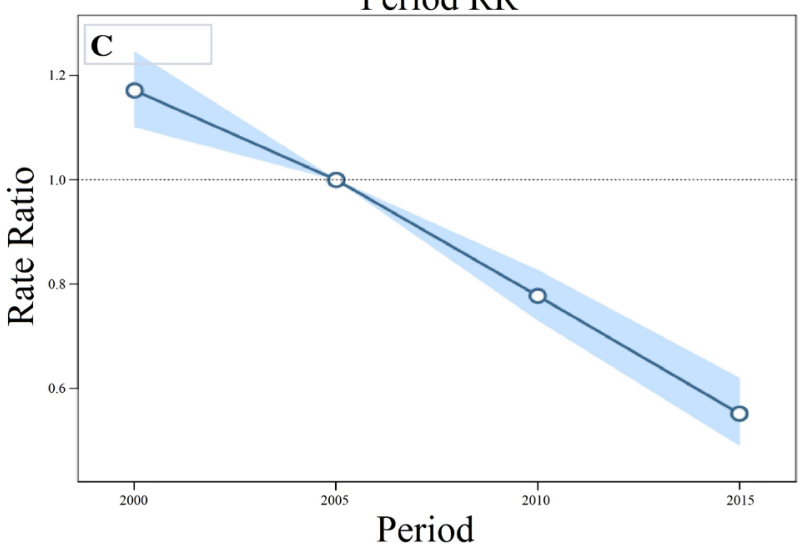

Local Drifts with Net Drift

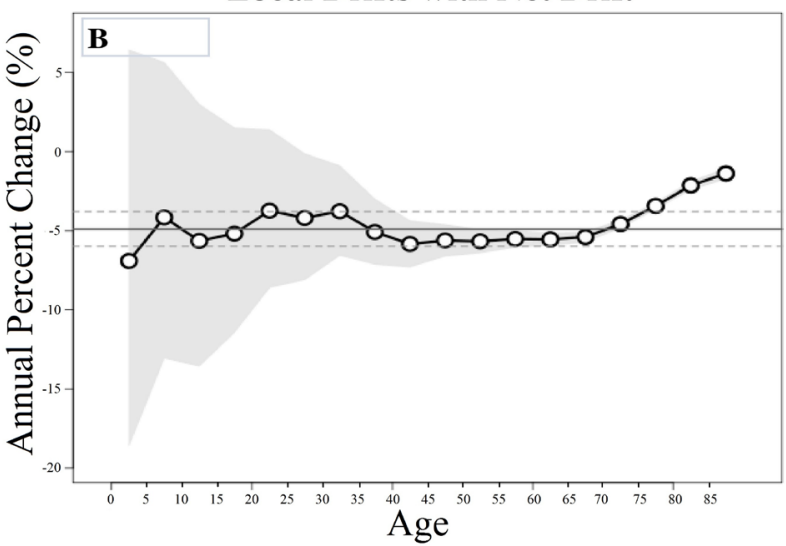

Cohort RR

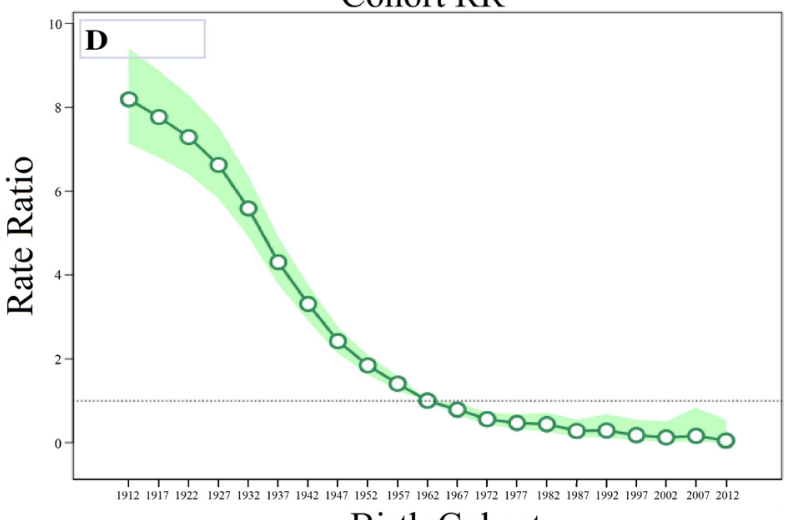

Birth Cohort

Figure 2 Mortality from cerebrovascular diseases in Serbia, in 1997-2016 period: an age-period-cohort analysis. (A) Longitudinal age curve of cerebrovascular diseases mortality rates: longitudinal age curve of the cerebrovascular diseases mortality rates (per 100000 persons) and the corresponding 95\% Cls (the area coloured in pink). (B) Local drift value for cerebrovascular diseases mortality rates: age group-specific annual per cent change (\%) in the cerebrovascular diseases mortality rates and the corresponding $95 \%$ Cls (the area coloured in grey). (C) Period effects on cerebrovascular diseases mortality rates: period effects obtained from age-period-cohort analyses for the cerebrovascular diseases mortality rates and the corresponding 95\% Cls (the area coloured in b/ue). (D) Cohort effects on cerebrovascular diseases mortality rates: cohort effects obtained from age-period-cohort analyses for the cerebrovascular diseases mortality rates and the corresponding $95 \%$ $\mathrm{Cls}$ (the area coloured in green). RR, rate ratio.

CVDs mortality showed statistically significant $(\mathrm{p}<0.05)$ cohort and period effects, as well as the net drift and local drifts in Serbia.

Age-period-cohort analysis of CVDs mortality by sex showed deviations from linearity for all three factors: age, period and cohort (see online supplementary table 1) . Deviations tended to distribute around approximately zero, except a slight deviation from zero that was observed for both sexes aged 0-4 years. In Serbia in both sexes, the risk of death from CVDs increased monotonically for people aged 50 years and over. The period effects have showed downward trends since 1997 in both sexes. The cohort effects decreased from 1912 to 2016 in both sexes (although these values were under one for the cohorts from 1967 onwards), with only a few insignificant exceptions for the 2007-2016 cohort in men and for the 1997-2016 cohort in women. The local drift values were above zero in all of the age groups of $30+$ years in men and $35+$ years in women, while an insignificant value was observed in the youngest age groups (data not shown).
The net drift was $-4.7 \%$ (95\% CI $-6.1 \%$ to $-3.2 \%$ ) in men, while in women it was $-5.2 \%$ (95\% CI $-6.9 \%$ to $-3.6 \%$ ). The Wald test indicated statistically significant period and cohort effects for both sexes, as well as all local drifts and net drift.

\section{DISCUSSION}

This study described CVDs mortality trends for Serbian population in the last two decades. After a decade of increase, CVDs mortality rates are finally declining in Serbia in both sexes and most age groups. Almost all of CVDs types significantly decreased, with the exception of cerebral infarction with a significant increase. Despite this, these rates place Serbia among the countries with the intermediate CVDs mortality rates in Europe.

Mortality rates for stroke vary significantly worldwide. In 2012, the highest rate was reported in Kyrgyzstan (186.9 per 100000 ), while the lowest rate of 2.2/100 000 was recorded in Qatar. ${ }^{25}$ Low mortality rates (about 20 
per 100000 or less) were recorded in both sexes in the USA, Japan, Australia. ${ }^{25}$ The ratio of CVDs mortality between several countries of the former Soviet Union and Latin America countries and most Western European countries is now over fourfold in both sexes. ${ }^{11}$ Age-standardised CVDs mortality rate in Serbian population of 121.8 per 100000 in 2012 is high compared with all of the countries in Western Europe or neighbouring countries (eg, Hungary 81.2, Croatia 96.8) ${ }^{10}$ In Serbian population, as well as in other populations, CVDs death rates were higher in males than in females. ${ }^{1025}$ International comparisons revealed that the standardised mortality rate for CVDs in the Serbian population showed alarming values in comparison with the entire European Union average in 2012 (121.8 vs 47.0 per 100000 persons, respectively). Although the differences in CVDs mortality rates between Serbia and other European countries could be, at least partly, attributed to the differences in quality of data collection and the potential coding and reporting errors for cause of death, they may indicate differences in incidence and survival rate for these diseases. ${ }^{1726-28}$ There are no data on CVDs incidence and survival of overall CVDs for the entire Serbia, except data on survival rate of ischaemic stroke in one study: the cumulative 28-day and 1-year survival rates of patients who had ischaemic stroke in the Belgrade cohort study were $81.0 \%$ and $78.3 \%$, respectively. ${ }^{29}$ In contrast, short-term and long-term stroke survival rates were higher in other studies. ${ }^{40}$ Many studies ${ }^{172627}$ have shown that there is a diversity in exposure to risk factors relating to CVDs, such as unhealthy lifestyles, smoking, obesity, blood pressure, dietary and other, as well as a diversity in health policy approaches to prevention and treatment of CVDs between high-income and low-income countries. Results of the 2013 National Health Survey of Serbia noted that the most frequent health problems in both sexes aged 15 and over were high blood pressure (35.2\% of women and $26.6 \%$ of men), elevated serum cholesterol (15.2\% of women and $10.5 \%$ of men), diabetes mellitus $(8.2 \%$ of women and $7.0 \%$ of men). ${ }^{31}$ Also, there were $40.4 \%$ of people with a normal nourishment level, while more than one half $(56.3 \%)$ were overweight, or preobese $(35.1 \%)$ and obese $(21.2 \%)$. In Serbia, with more than one half of the population smoking in some part of their lives (51.8\%), tobacco use has, for a number of years, been one of the risk factors with the highest prevalence in the world. ${ }^{31} 32$ Besides that, Serbia is among countries with the oldest population in Europe, with the share of people aged 65 years and over in the total population of Serbia being $17.4 \% .^{33}$

Our results show a significant age effect for both sexes similarly. This pattern reflects demographic, epidemiological and healthcare transitions that took place in Serbia and many other former Eastern Bloc countries in the beginning of the 21 st century. ${ }^{71}$ Increasing age is one of the main unmodifiable risk factors for CVDs. ${ }^{4}$ In addition, the number of modifiable risk factors for CVDs, including hypertension, cholesterol and obesity, rises with age. Among all, the hypertension is the main risk factor for CVDs in people of all ages and in particular in the elderly. In Serbia in 2000, 2006 and 2013, the prevalence of hypertension was $19.7 \%, 23.1 \%$ and $33.2 \%$ among the population aged 20 and over, respectively. ${ }^{31}$ Also, prevalence of hypertension was around $35 \%$ among men and women for the 25-64years age group, and $75 \%$ among men and women of more than 65 years of age. ${ }^{31}$ Also, a considerably higher percentage of overweight persons was recorded in all age groups, from 45 to 84 .

Stroke mortality trend has significantly declined in the past few decades in developed countries: the USA, ${ }^{49}$ Japan $^{34}$ and West European countries. ${ }^{10}{ }^{11}$ Contrary, in East European countries there has been a constant increase in mortality rate caused by stroke during the last decades of the 20th century which continued in decreasing trend in the recent decade. ${ }^{1025} 27$ After a decade of increase, CVDs mortality rates have significantly declined in the last decade in Serbia in both sexes. There was a slightly greater decline in age-adjusted stroke death rates in women than in men in almost all of the countries, except few only, such as Denmark and Ecuador. ${ }^{11}$ Trends in mortality from CVDs declined more in people younger than 70 years than in those aged 70 years or older, both in men and women in Serbia. Interpretation of CVDs mortality trends is complex, and it is unlikely related to the changes in death certification alone, but likely depends on wide geographical and temporal variations in incidence and survival rate for these diseases. The risk factors most responsible for the burden of CVDs in Serbia were smoking, physical inactivity, hypertension and overweight/obesity. ${ }^{35}$ Serbian national guidelines for the diagnosis and treatment of arterial hypertension from 2012 are expected to lead to further effective control of blood pressure. ${ }^{36}$ Similar to former communist countries, Serbia underwent a more rapid ageing process than Western European societies. ${ }^{33}$ Potential reasons for the decline in stroke mortality largely included a better stroke prevention with improvements in acute stroke treatment in developed countries. ${ }^{151737}$

Many studies ${ }^{627}$ confirmed the persistence of steady declines in all types of CVDs mortality in Western Europe, North America, Japan and other developed areas of the world. Ischaemic stroke mortality decreased by $37 \%$ in high-income countries and by $14 \%$ in low-income and middle-income countries, while haemorrhagic stroke mortality decreased by $38 \%$ in high income countries and by $23 \%$ in low-income and middle-income countries ${ }^{6}$ but there are some differences in CVDs mortality trends: ICH showed a faster decrease in mortality than cerebral infarction during the past decades in Japan ${ }^{27}$ which may be at least partly attributed to effective management of hypertension, one of the major risk factors for ICH. ${ }^{38}$ Similar to findings noticed in China, ${ }^{39}$ the trends in mortality rates for almost all of CVDs types significantly decreased in Serbia, with the exception of cerebral infarction with a significant increase in both sexes. Differences in mortality trends for stroke subtypes may be attributed to lower 
precision in their diagnoses because low-income and middle-income countries have disadvantages compared with developed areas. ${ }^{45}$ One potential reason for differences in mortality trends for stroke types might be explained by the widespread use of CT and MRI over past decades. ${ }^{40}$ Also, there are differences in the prevalence of risk factors for haemorrhagic and ischaemic stroke. ${ }^{41}$

The reduction of mortality from CVDs in Europe and most western countries during the last decades of the 20th century, as described by the classical model of epidemiological transition, was determined primarily by changes in lifestyle and socioeconomic factors. ${ }^{37} 4243$ The mortality decline in currently low-income and middle-income countries (such as Serbia and some East European countries) has been more recent and is linked to the contemporary or delayed transition model. Numerous data illustrate evolution of the smoking epidemic and trends of other coronary risk factors in Serbian population. ${ }^{31}{ }^{44}$ The WHO Monitoring of Trends and Determinants in Cardiovascular Disease study showed that female smoking rates and systolic blood pressure have been increasing in Serbia over the 1984-1995 period, upward trend in body mass index was present in the male population, while total cholesterol increased in both sexes aged 35-64 years. ${ }^{44}$ The results of the National Health Survey showed that the prevalence of hypertension, elevated blood cholesterol and diabetes increased among the population aged 20 and over in Serbia in the 2000-2013 period. ${ }^{31}$ The percentage of daily smokers is lower in $2013(29.2 \%)$ than in $2000(33.0 \%)$, but considerable increase was noted in comparison with 2006 (26.2\%) for both sexes in Serbia. ${ }^{31}$

The Serbian National Guidelines for good clinical practice for the arterial hypertension, ischaemic stroke and CVDs prevention have been implemented since 2005, when primary and secondary prevention targets and practical guidelines were set out. ${ }^{31}$ Every other person with hypertension or potential hypertension $(51.3 \%)$ was taking antihypertensive drugs in 2006 which is considerably more than in $2000(46.5 \%) .{ }^{31}$ Unfortunately, it was only in the last decade that some organised tobacco control measures were implemented in Serbia which have been intensified since the WHO Convention on Tobacco Control entered into force in Serbia in 2006 and the Law on Protection of Population from Exposure to Tobacco Smoke passed in 2010. ${ }^{45}$ Consequently, age-standardised estimated prevalence of tobacco smoking among those aged 15 years or more was $32.6 \%$ in Serbia in 2015 which is considerably more than in 2006 (26.2\%) and $2013(29.2 \%){ }^{31}{ }^{32}$ The rising tobacco smoking prevalence in Serbia is in sharp contrast with the overall decline in the western industrial nations. ${ }^{32}$ In Serbia, the tremendous impact of smoking epidemic on mortality from CVDs (trend from cerebral infarction, particularly) has been magnified by population ageing, huge social and economic changes and lack of comprehensive public health programmes. ${ }^{31} 4244$ It is generally accepted that the differences in trends in mortality from CVDs subtypes seen in developed countries since 1960s can be explained in large part by reductions in incidence, extensive control of hypertension and other risk factors (such as smoking, alcohol consumption and diet) and higher survival rates. ${ }^{6} 4748$ In contrast, the highest mortality rates from CVDs in Serbia and some countries of the former Eastern Bloc, likely reflect the rapid social and economic changes during the transition period since 1990s. ${ }^{42}$ The main contributor to the increase in mortality trend of ischaemic stroke in Serbia probably was high smoking prevalence. ${ }^{31}$ The mortality rate from ischaemic stroke began to decline earlier in countries where tobacco control began to be implemented earlier (such as the USA, the UK, Finland). ${ }^{611} 44$

Age-period-cohort models are used to evaluate the changes in the CVDs mortality rates and provide a possibility to explain the observed trends. ${ }^{49-51}$ Variations in CVDs mortality could be explained by changes in factors that act around the time of death (period effect) and by risk factors and environmental exposures that are present in early life (cohort effect). Similar to some other countries, ${ }^{52} 53$ the CVDs mortality rates in Serbia are associated with age, period and cohort effects. The largely expanding elderly population correlates to the age effect on stroke mortality observed in this study. Although the influence of small numbers on assessed mortality can not be excluded, the deaths noted in Serbian population indicate that young age groups should be targeted for stroke prevention programmes. A large proportion of the recent acceleration of declining trends in CVDs mortality since 2005 in Serbia can be correlated to favourable changes in risk factors exposure, improved socioeconomic situation as well as significant improvements of medical care services (such as the emergency services, CT or MRI) that are more available and accessible for diagnosis and treatment. ${ }^{31} 3654$ Conversely, cause-of-death coding practice, which did not change during the observed period, could not have influenced CVDs mortality trends. The onset of the mortality decline in CVDs for cohorts born at the beginning of the 20th century seems to indicate a contribution of the improvements in living and social conditions in early life, as well as the improved medical care (increased uptake of preventive medication such as antihypertensives, lipid-lowering drugs and antiplatelets) and the effective control of risk factors (declines in smoking prevalence). The underlying reasons for the decelerating cohort effect happening since the 1960s were the rising prevalence of the risk factors (hypertension, obesity, diabetes mellitus, cholesterol level, smoking, the sedentary lifestyle)..$^{3155}$

\section{The strengths and limitations of the study}

The strengths of the present study include the national representation of CVDs mortality, the quality of the national death registry data ${ }^{56}$ the analysis of stroke mortality by different subtypes of stroke and the application of two methods (joinpoint regression method 
and age-period-cohort method) for the analysis of CVDs mortality trends.

This present study had several limitations. Of course, quality of data is always a question. The disease coding procedures changed in 1997, and the ICD-10 coding was introduced. Although data on stroke mortality were analysed using the unique death statistics in whole period studied, the influence of the change in coding can not be completely excluded in estimates of the mortality rates by the type of stroke. In the absence of national data on stroke incidence and survival, it is difficult to completely evaluate the changes in stroke mortality trends in Serbia. Although the number of refugees in Serbia generally decreased during the observed period, since there are no separate data on mortality from CVDs in refugees, this could confound the CVDs mortality pattern in Serbia. The relatively short study period may result in imprecise estimations of the age-period-cohort effects on CVDs mortality. Further, limitation of our study is inability to determine which factors are responsible for the observed age, period and cohort effects. In this study, the socioeconomic and other data (eg, occupation, marital status, smoking, comorbidity) that could improve understanding of CVDs mortality in Serbia are not available. It can be assumed that diagnostics of CVDs was worse during the first years of the observed period (from 1997 to 2000) than during the recent years because of the war and economic crisis in the country. Unfavourable trends in mortality from CVDs in Serbia could be attributed primarily to mortality from cerebral infarction. The trends of deaths from cerebral infarction in Serbia might have been a consequence of unfavourable circumstances specific to the country's sociopolitical fluctuations during the observed period, namely the marked decline in the general standard of living, the unsatisfactory quality of health services (including a lack of drugs, medical equipment, a large increase in refugees requiring medical and social care, decreasing hospitalisation rates, particularly for people aged over 60 years), social disintegration, ageing of the population. The relatively favourable trend in mortality from SAH and ICH, on the other hand, may be attributed to the improvements in hypertension treatment in Serbia. Further, limitation is the inherent limitation of age-period-cohort analysis, such as collinearity among age, period and cohort effects. Also, temporal trend analysis was an ecological descriptive analysis at the population level which does not have to necessarily apply to individuals.

\section{CONCLUSION}

CVDs mortality trend decreased in Serbia in the last decades. An acceleration in decreasing of rates in the most recent period is especially promising but mortality rates from CVDs remain exceedingly high in Serbia. Further efforts in the primary and secondary prevention to reduce mortality from CVDs in Serbian population are required, especially for cerebral infarction.
Acknowledgements This work was supported by Ministry of Education, Science and Technological Development, Republic of Serbia, 2011-2016 (contract no 175042).

Contributors Study conception and design: II, MI. Acquisition of data: MI. Analysis and interpretation of data: II, MI. Drafting of manuscript: II, MI. Critical revision: II, MI, SSG. All authors read and approved the final manuscript.

Funding The authors have not declared a specific grant for this research from any funding agency in the public, commercial or not-for-profit sectors.

Competing interests None declared.

Patient consent for publication Not required.

Ethics approval This study was approved by the Ethics Committee of the Faculty of Medical Sciences, University of Kragujevac (protocol: 01-4801).

Provenance and peer review Not commissioned; externally peer reviewed.

Data sharing statement No data are available.

Open access This is an open access article distributed in accordance with the Creative Commons Attribution Non Commercial (CC BY-NC 4.0) license, which permits others to distribute, remix, adapt, build upon this work non-commercially, and license their derivative works on different terms, provided the original work is properly cited, appropriate credit is given, any changes made indicated, and the use is non-commercial. See: http://creativecommons.org/licenses/by-nc/4.0/.

\section{REFERENCES}

1. World Health Organization. The top 10 causes of death, Fact sheet. http://www.who.int/mediacentre/factsheets/fs310/en/ (Accessed 2 March 2018).

2. World Health Organization. Cardiovascular diseases (CVDSs), Fact sheet. http://www.who.int/mediacentre/factsheets/fs317/en/ (Accessed 2 Mar 2018).

3. World Health Organization. Global Health Estimates 2015: deaths by cause, Age, Sex, by Country and by Region, 2000-2015. Geneva, Switzerland: World Health Organization, 2016.

4. Mozaffarian D, Benjamin EJ, As G, et al. American Heart Association Statistics Committee and Stroke Statistics Subcommittee. Heart disease and stroke statistics -2015 update: a report from the American Heart Association. Circulation 2015;131:e29-e322.

5. Feigin VL. Stroke epidemiology in the developing world. Lancet 2005;365:2160-1.

6. Krishnamurthi RV, Feigin VL, Forouzanfar $\mathrm{MH}$, et al. Global and regional burden of first-ever ischaemic and haemorrhagic stroke during 1990-2010: findings from the Global Burden of Disease Study 2010. Lancet Glob Health 2013;1:e259-81.

7. Townsend N, Nichols M, Scarborough P, et al. Cardiovascular disease in Europe--epidemiological update 2015. Eur Heart $J$ 2015;36:2696-705.

8. Heron M. Deaths: Leading Causes for 2015. Natl Vital Stat Rep 2017;66:1-76.

9. Gupta R, Joshi P, Mohan V, et al. Epidemiology and causation of coronary heart disease and stroke in India. Heart 2008;94:16-26.

10. World Health Organization. Regional Office for Europe. European Health for All Database (HFA-DB). Copenhagen, Denmark: WHO Regional Office for Europe.

11. Levi F, Chatenoud L, Bertuccio P, et al. Mortality from cardiovascular and cerebrovascular diseases in Europe and other areas of the world: an update. Eur J Cardiovasc Prev Rehabil 2009;16:333-50.

12. Wang Z, Hu S, Sang S, et al. Age-Period-cohort analysis of stroke mortality in china: data from the global burden of disease study 2013. Stroke 2017;48:271-5.

13. GBD 2015 Mortality and Causes of Death Collaborators. Global, regional, and national life expectancy, all-cause mortality, and causespecific mortality for 249 causes of death, 1980-2015: a systematic analysis for the Global Burden of Disease Study 2015. Lancet 2016;388:1459-544.

14. Mozaffarian D, Benjamin EJ, Go AS, et al. Heart disease and stroke statistics-2016 update: a report from the American heart association. Circulation 2016;133:e38-360.

15. Bennett DA, Krishnamurthi RV, Barker-Collo S, et al. The global burden of ischemic stroke: findings of the GBD 2010 study. Glob Heart 2014;9:107-12.

16. Cruz C, Campuzano-Rincón JC, Calleja-Castillo JM, et al. Temporal Trends in Mortality from Ischemic and Hemorrhagic Stroke in Mexico, 1980-2012. J Stroke Cerebrovasc Dis 2017;26:725-32. 
17. Luepker RV, Arnett DK, Jacobs DR, et al. Trends in blood pressure, hypertension control, and stroke mortality: the minnesota heart survey. Am J Med 2006;119:42-9.

18. Vlajinac HD, Adanja BJ, Jarebinski MS, et al. Cardiovascular disease mortality in Belgrade: trends from 1975-89. J Epidemiol Community Health 1994;48:254-7.

19. Pekmezovic T, Tepavcevic DK, Jarebinski M, et al. Stroke mortality in Belgrade, Serbia: age, period, and cohort analyses. Cerebrovasc Dis 2007;24:191-5.

20. Kim HJ, Fay MP, Feuer EJ, et al. Permutation tests for joinpoint regression with applications to cancer rates. Stat Med 2000;19:335-51.

21. Lerman PM. Fitting segmented regression models by grid search. Appl Stat 1980;29:77-84.

22. Clegg LX, Hankey BF, Tiwari R, et al. Estimating average annual per cent change in trend analysis. Stat Med 2009;28:3670-82.

23. Kim HJ, Fay MP, Yu B, et al. Comparability of segmented line regression models. Biometrics 2004;60:1005-14.

24. Rosenberg PS, Check DP, Anderson WF. A web tool for age-periodcohort analysis of cancer incidence and mortality rates. Cancer Epidemiol Biomarkers Prev 2014;23:2296-302.

25. Thrift AG, Thayabaranathan T, Howard G, et al. Global stroke statistics. Int J Stroke 2017;12:13-32.

26. Truelsen T, Krarup LH, Iversen HK, et al. Causes of death data in the global burden of disease estimates for ischemic and hemorrhagic stroke. Neuroepidemiology 2015;45:152-60.

27. Heidrich J, Heuschmann PU, Kolominsky-Rabas P, et al. Variations in the use of diagnostic procedures after acute stroke in Europe: results from the BIOMED II study of stroke care. Eur J Neurol 2007;14:255-61.

28. Thrift AG, Howard G, Cadilhac DA, et al. Global stroke statistics: An update of mortality data from countries using a broad code of "cerebrovascular diseases". Int J Stroke 2017;12:796-801.

29. Medic S, Beslac-Bumbasirevic L, Kisic-Tepavcevic D, et al. Shortterm and long-term stroke survival: the belgrade prognostic study. $J$ Clin Neurol 2013;9:14-20.

30. Andersen KK, Andersen ZJ, Olsen TS. Predictors of early and late case-fatality in a nationwide Danish study of 26,818 patients with first-ever ischemic stroke. Stroke 2011;42:2806-12.

31. Ministry of Health, Republic of Serbia. National Health survey, Serbia 2013. Belgrade: Ministry of Health, Republic of Serbia, 2014.

32. World Health Organization. WHO report on the global tobacco epidemic, 2015. Geneva, Switzerland: WHO Press, World Health Organization., 2015.

33. Eurostat. Europe in figures - eurostat yearbook. Luxembourg, Luxembourg: European Commission, 2016.

34. Pham TM, Fujino Y, Kubo T, et al. Premature mortality due to stroke and trend in stroke mortality in Japan (1980-2005). Eur J Public Health 2011;21:609-12.

35. Vlajinac $\mathrm{H}$, Sipetic $\mathrm{S}$, Saulic A, et al. Burden of ischaemic heart disease and cerebrovascular diseases in Serbia without Kosovo and Metohia, 2000. Eur J Cardiovasc Prev Rehabil 2006;13:753-9.

36. Ministry of Health, Republic of Serbia. A national guide to good clinical practice for the diagnosis and treatment of arterial hypertension. Serbia, Belgrade: Ministry of Health, Republic of Serbia, 2012

37. Towfighi A, Saver JL. Stroke declines from third to fourth leading cause of death in the United States: historical perspective and challenges ahead. Stroke 2011;42:2351-5.
38. Imano H, Kitamura A, Sato S, et al. Trends for blood pressure and its contribution to stroke incidence in the middle-aged japanese population: the Circulatory Risk in Communities Study (CIRCS). Stroke 2009;40:1571-7.

39. Tian D, Yang Q, Dong Q, et al. Trends in stroke subtypes and vascular risk factors in a stroke center in China over 10 years. Sci Rep 2018;8:5037.

40. Feigin VL, Krishnamurthi RV, Barker-Collo S, et al. 30-Year trends in stroke rates and outcome in Auckland, New Zealand (19812012): a multi-ethnic population-based series of studies. PLoS One 2015;10:e0134609.

41. Owolabi MO, Sarfo F, Akinyemi R, et al. Dominant modifiable risk factors for stroke in Ghana and Nigeria (SIREN): a case-control study. Lancet Glob Health 2018;6:e436-46.

42. Sarti C, Rastenyte D, Cepaitis Z, et al. International trends in mortality from stroke, 1968 to 1994. Stroke 2000;31:1588-601.

43. Ezzati M, Obermeyer Z, Tzoulaki I, et al. Contributions of risk factors and medical care to cardiovascular mortality trends. Nat Rev Cardiol 2015;12:508-30.

44. Evans $\mathrm{A}$, Tolonen $\mathrm{H}$, Hense $\mathrm{HW}$, et al. Trends in coronary risk factors in the WHO MONICA project. Int J Epidemiol 2001;30:S35-40.

45. Statistical Office of the Republic of Serbia. Demographic yearbook, 2015. Belgrade: Statistical Office of the Republic of Serbia, 2016.

46. Official Gazette. Law on protection of the population from exposure to tobacco smoke, "official gazette of RS", No. 2010;30.

47. Yusuf S, Reddy S, Ounpuu S, et al. Global burden of cardiovascular diseases: part I: general considerations, the epidemiologic transition, risk factors, and impact of urbanization. Circulation 2001:104:2746-53.

48. Danaei G, Singh GM, Paciorek CJ, et al. Global burden of metabolic risk factors of chronic diseases collaborating group. the global cardiovascular risk transition: associations of four metabolic risk factors with national income, urbanization, and western diet in 1980 and 2008. Circulation 2013;127:502-14938.

49. Ocaña-Riola R, Blanco-Reina E, Navarro-Moreno E, et al. Ageperiod-cohort effects on mortality from cerebrovascular disease in southern Spain. J Stroke Cerebrovasc Dis 2014;23:2274-82.

50. Sutton CJ, Marsden J, Watkins CL, et al. Changing stroke mortality trends in middle-aged people: an age-period-cohort analysis of routine mortality data in persons aged 40 to 69 in England. $J$ Epidemiol Community Health 2010;64:523-9.

51. Ma E, Takahashi H, Mizuno A, et al. Stratified age-period-cohort analysis of stroke mortality in Japan, 1960 to 2000. J Stroke Cerebrovasc Dis 2007;16:91-102.

52. Wang Z, Hu S, Sang S, et al. Age-period-cohort analysis of stroke mortality in China: data from the global burden of disease study 2013. Stroke 2017:48:271-5.

53. Janssen F, Kunst AE. Netherlands epidemiology and demography compression of morbidity research group. cohort patterns in mortality trends among the elderly in seven european countries, 1950-99. Int J Epidemiol 2005;34:1149-59.

54. Ministry of Health, Republic of Serbia. A national guide to good clinical practice for the diagnosis and treatment of ischemic stroke. Serbia, Belgrade: Ministry of Health, Republic of Serbia, 2012.

55. Vlajinac $H$, Adanja B, Jarebinski M. Smoking habits of Belgrade urban population. Med Invest 1990;23:73-6.

56. Mathers CD, Fat DM, Inoue M, et al. Counting the dead and what they died from: an assessment of the global status of cause of death data. Bull World Health Organ 2005;83:171-7. 